\title{
The effects of dietary fibre type on satiety-related hormones and voluntary food intake in dogs
}

\author{
Guido Bosch ${ }^{1}$, Adronie Verbrugghe ${ }^{2}$, Myriam Hesta ${ }^{2}$, Jens J. Holst ${ }^{3}$, Antonius F. B. van der Poel ${ }^{1}$, \\ Geert P. J. Janssens ${ }^{2}$ and Wouter H. Hendriks ${ }^{1}$ \\ ${ }^{1}$ Animal Nutrition Group, Department of Animal Sciences, Wageningen University, PO Box 338, 6700 AH Wageningen, The \\ Netherlands \\ ${ }^{2}$ Laboratory of Animal Nutrition, Faculty of Veterinary Medicine, Ghent University, Heidestraat 19, B-9820 Merelbeke, Belgium \\ ${ }^{3}$ Department of Biomedical Sciences, The Panum Institute, University of Copenhagen, Blegdamsvej 3, DK-2200 Copenhagen, \\ Denmark
}

(Received 15 July 2008 - Revised 31 October 2008 - Accepted 2 November 2008 - First published online 15 January 2009)

Depending on type and inclusion level, dietary fibre may increase and maintain satiety and postpone the onset of hunger. This 7-week study evaluated the effect of fibre fermentability on physiological satiety-related metabolites and voluntary food intake (VFI) in dogs. Sixteen healthy adult dogs were fed a low-fermentable fibre (LFF) diet containing $8.5 \%$ cellulose or a high-fermentable fibre (HFF) diet containing $8.5 \%$ sugarbeet pulp and $2 \%$ inulin. Large intestinal fibre degradation was evaluated by apparent faecal digestibility of nutrients and faecal $\mathrm{SCFA}$ and $\mathrm{NH}_{3}$ concentrations. Postprandial blood samples were obtained to determine postprandial plasma glucose, insulin, total peptide tyrosine-tyrosine (PYY), total glucagon-like peptide-1 (GLP-1) and total ghrelin concentrations. At the end of the study, the dogs were given a single meal of a dry dog food to determine VFI. Dogs fed the HFF diet had a significantly higher large intestinal fibre degradation and production of SCFA compared with the dogs fed the LFF diet. The HFF-fed dogs tended $(P=0.058)$ to show a lower VFI at the end of the study. No treatment effects were found for postprandial plasma glucose, PYY, GLP-1 and ghrelin responses. The concentrations of these metabolites could not be related to the observed difference in VFI. The inclusion of fermentable fibre in canine diets may contribute to the prevention or mitigation of obesity through its effects on satiety. The underlying mechanisms require further investigation.

Dietary fibre type: Dogs: Satiety hormones: Insulin

Obesity is the most common nutritional disorder in companion animals nowadays ${ }^{(1)}$. Studies conducted in different countries (e.g. England, Australia, USA) have estimated the incidence of overweight and obesity in the dog population between 22 and $40 \%{ }^{(2)}$. The cause of overweight and obesity is a chronic energy intake that exceeds energy expenditure. Dietary fibre may aid in the mitigation and prevention of obesity as it may increase and maintain satiety and prevent the feeling of hunger in the dogs. The feeling of hunger may result in an increase in begging and scavenging behaviour ${ }^{(3)}$, which may in turn encourage the owners to feed their pet more than the animal's physiological energy requirement ${ }^{(4)}$.

Several studies have evaluated the effect of dietary fibre on satiety in the dogs. Jewell \& Toll $^{(4)}$ and Jackson et al. ${ }^{(5)}$ showed a reduced daily energy intake when the dogs were fed high-fibre diets. In addition, voluntary food intake (VFI) of an additional meal $75 \mathrm{~min}$ after consumption of the morning meal was lower in the dogs fed high-fibre diets ${ }^{(4)}$. No effect of dietary fibre on VFI in the dogs was found by Butterwick
$\&$ Markwell $^{(6)}$. However, the dogs in the latter study were overweight and supplied with approximately $45 \%$ of calculated maintenance energy requirements at target body weight $(\mathrm{BW})$ to induce weight loss. This restriction in daily energy intake may have resulted in an increased feeding motivation to a level that nullified possible effects of dietary fibre on satiety ${ }^{(5)}$.

Several physical and chemical properties of dietary fibres may influence the duration of postprandial satiety. Fibre fermentability yielding SCFA may affect satiety through its actions on the production and secretion of gastrointestinal satiety hormones. Infusion of SCFA in the colon of rats ${ }^{(7)}$ and oleic acid in the colon of $\operatorname{dogs}^{(8)}$ increased peripheral peptide tyrosine-tyrosine (PYY) concentrations. PYY can cross the blood-brain barrier and act on the arcuate nucleus of the hypothalamus, stimulating neurons that create a sensation of satiety and inhibiting neurons that stimulate feeding behaviour ${ }^{(9)}$. Stimulation of the secretion of glucagon-like peptide-1 (GLP-1), a proglucagon-derived peptide secreted by the enteroendocrine L-cells present in the

Abbreviations: ADC, apparent digestibility coefficient; ADF, acid-detergent fibre; AUC, area under the curve; BW, body weight; GLP-1, glucagon-like peptide-1; HFF, high-fermentable fibre; LFF, low-fermentable fibre; NDF, neutral-detergent fibre; PYY, peptide tyrosine-tyrosine; TDF, total dietary fibre; VFI, voluntary food intake.

*Corresponding author: Guido Bosch, fax +31317484260, email guido.bosch@wur.nl 
distal part of the gastrointestinal tract ${ }^{(10)}$, was increased by the inclusion of fermentable fibres in the diets of dogs during an oral glucose tolerance test ${ }^{(11)}$. Both PYY and GLP-1 contribute to the ileal brake and increase gastric emptying time and small intestinal transit time ${ }^{(12)}$. This may prolong gastric distension and signals of satiation ${ }^{(13)}$ and prolong the contact between nutrients and small intestinal receptors involved in maintaining satiety $^{(14)}$. A delay in gastric emptying will also delay starch digestion and subsequent absorption of glucose ${ }^{(15)}$, thereby maintaining more stable postprandial glucose and insulin concentrations in the blood ${ }^{(16)}$. Sows fed a diet high in sugarbeet pulp had more stable postprandial glucose concentrations compared with those fed a low-fibre diet that showed a drop in glucose concentration below basal levels. This was associated with an increase in physical activity possibly caused by the feelings of hunger ${ }^{(17)}$. Fermentable fibres have also been found to affect peripheral ghrelin concentrations, a hormone correlated with hunger or appetite ${ }^{(18)}$. Rats fed diets supplemented with a short-chain oligofructose showed lower active ghrelin plasma concentrations $8 \mathrm{~h}$ after the last meal compared with those fed the diet without fructan supplementation ${ }^{(19)}$.

There is still little information available regarding the potency of various fermentable fibres to affect the satiety in dogs. The aim of the present study was therefore to investigate whether an increase in dietary fibre fermentability prolongs the duration of postprandial satiety as measured by VFI and physiological satiety metabolites when included in the diets of dogs.

\section{Experimental methods \\ Animals}

Sixteen (eight males and eight females) healthy adult beagle dogs aged between 2 and 6 years with an initial BW between 7.2 and $11.4 \mathrm{~kg}$ were individually housed in indoor pens at the Laboratory of Animal Nutrition of Ghent University (Merelbeke, Belgium). Dietary treatments were equally distributed among pens. The dogs were assigned to one of two dietary treatments (low-fermentable fibre (LFF) or high-fermentable fibre (HFF)) according to BW and sex (blocking factors) resulting in a mean BW of 9.7 (SEM 0.5) and 9.7 (SEM 0.4) $\mathrm{kg}$ for the LFF and the HFF groups, respectively. All the dogs were weighed before the start of the experiment and thereafter every 2 weeks until the end of the experiment. Each dog was fed individually to meet its maintenance energy requirement estimated at $415 \mathrm{~kJ}$ metabolisable energy $/ \mathrm{kg} \mathrm{BW}^{0.75}(20)$. The diets were fed twice daily in two equal portions at 08.30 and 18.30 hours after mixing with an equal amount of lukewarm water to increase palatability. Food intake was recorded during each meal throughout the entire experimental period and freshwater was provided ad libitum. All animal housing, care and experimental procedures were approved by and conformed to the requirements of the Ethical Committee of the Faculty of Veterinary Medicine of the Ghent University (Belgium, EC 2007/40).

\section{Diets}

The dogs were fed one of the two experimental diets formulated to be iso-nitrogenous and iso-energetic on a metabolisable energy basis, and iso-fibrous on a total dietary fibre (TDF) basis. Ingredient composition of both diets is shown in Table 1. The LFF diet contained cellulose as a fibre source, whereas the HFF diet contained a combination of sugarbeet pulp and inulin. Differences in fermentability between fibre sources used were based on the in vitro studies ${ }^{(21,22)}$. The content of molasses in the sugarbeet pulp was estimated to be $5 \%$ and an identical amount of molasses was added to the $\mathrm{LFF}$ diet. $\mathrm{TiO}_{2}(2 \mathrm{~g} / \mathrm{kg}$ diet $)$ was included as an inert digestibility marker ${ }^{(23)}$.

\section{Chemical analyses}

The diets were analysed for DM, ash, starch, sugar, crude protein, crude fat, TDF, insoluble dietary fibre, neutral-detergent fibre

Table 1. Composition of the low-fermentable fibre (LFF) and highfermentable fibre (HFF) diets

\begin{tabular}{|c|c|c|}
\hline & LFF & HFF \\
\hline \multicolumn{3}{|l|}{ Ingredient composition ( $\mathrm{g} / \mathrm{kg}$ as is) ${ }^{*}$} \\
\hline Wheat starch (pre-gelatinised) & $468 \cdot 75$ & $463 \cdot 00$ \\
\hline Poultry meat meal (low ash) & 285.00 & $275 \cdot 00$ \\
\hline Poultry fat & $135 \cdot 00$ & $135 \cdot 00$ \\
\hline Cellulose & $85 \cdot 00$ & - \\
\hline Sugarbeet pulp (molassed) & - & $85 \cdot 00$ \\
\hline Inulin & - & $20 \cdot 00$ \\
\hline Premix $†$ & $10 \cdot 00$ & $10 \cdot 00$ \\
\hline Digest & $10 \cdot 00$ & $10 \cdot 00$ \\
\hline Molasses & $4 \cdot 25$ & - \\
\hline Titanium(IV) oxide & 2.00 & $2 \cdot 00$ \\
\hline \multicolumn{3}{|l|}{ Nutrient composition (g/kg DM) } \\
\hline Ash & 37.5 & $42 \cdot 0$ \\
\hline Starch & $372 \cdot 4$ & $367 \cdot 5$ \\
\hline Sugar & $13 \cdot 6$ & $41 \cdot 6$ \\
\hline Crude protein & $274 \cdot 1$ & $262 \cdot 2$ \\
\hline Crude fat & 191.4 & $191 \cdot 2$ \\
\hline TDF & $123 \cdot 7$ & 93.9 \\
\hline IDF & $110 \cdot 9$ & $74 \cdot 7$ \\
\hline SDF $\ddagger$ & $12 \cdot 8$ & $19 \cdot 2$ \\
\hline NDF & $139 \cdot 4$ & 99.5 \\
\hline ADF & 93.9 & $41 \cdot 7$ \\
\hline ADL & $11 \cdot 1$ & $10 \cdot 8$ \\
\hline NSP§ & $111 \cdot 0$ & $95 \cdot 1$ \\
\hline \multicolumn{3}{|l|}{ Energy content (kJ/100 g DM) } \\
\hline Gross energy & 2294 & 2300 \\
\hline
\end{tabular}

TDF, total dietary fibre; IDF, insoluble dietary fibre; SDF, soluble dietary fibre; NDF, neutral-detergent fibre; ADF, acid-detergent fibre; ADL, acid-detergent lignin. *Wheat starch, Pregel Wheat Alpha (Meneba, Weert, The Netherlands); poultry meat meal, Meat Meal 63 (Sonac, Lingen, Germany); poultry fat (Sonac, Lingen, Germany); cellulose, Arbocel BWW40 (J. Rettenmaier Benelux, Zutphen, The Netherlands); sugarbeet pulp, molasses (Research Diet Services, Wijk bij Duurstede, The Netherlands); inulin, Beneo IPS (Orafti, Tienen, Belgium); premix (Twilmij B.V., Stroe, The Netherlands); digest, Luxus Digest N8008 (AFB International, Nuland, The Netherlands); titanium(IV) oxide (Sigma-Aldrich Chemie B.V., Zwijndrecht, The Netherlands).

†The premix provided per kilogram of diet: $\mathrm{Ca}, 0.41 \mathrm{~g} ; \mathrm{P}, 0.07 \mathrm{~g} ; \mathrm{Mg}, 0.05 \mathrm{~g} ; \mathrm{K}$ $0.1 \mathrm{~g} ; \mathrm{Na}, 0.01 \mathrm{~g} ; \mathrm{Cl}, 0.09 \mathrm{~g}$; linoleic acid, $0.15 \mathrm{~g}$; PUFA, $0.17 \mathrm{~g}$; lysine, $0.05 \mathrm{~g}$ methionine, $0.02 \mathrm{~g}$; methionine + cysteine, 0.04 ; threonine, $0.04 \mathrm{~g}$; tryptophan, $0.02 \mathrm{~g}$; retinol, $5.25 \mathrm{mg}$; vitamin $\mathrm{D}_{3}, 50 \mu \mathrm{g}$; vitamin $\mathrm{E}, 100 \mathrm{mg}$; vitamin $\mathrm{K}_{3}, 2 \mathrm{mg}$ vitamin $B_{1}, 10 \mathrm{mg}$; vitamin $B_{2}, 10 \mathrm{mg}$; niacin, $50 \mathrm{mg}$; pantothenic acid, $25 \mathrm{mg}$ vitamin $B_{6}, 7.5 \mathrm{mg}$; vitamin $\mathrm{B}_{12}, 50 \mu \mathrm{g}$; biotin, $300 \mu \mathrm{g}$; choline chloride, $475 \mathrm{mg}$; folic acid, $1.25 \mathrm{mg}$; vitamin C, $100 \mathrm{mg}$; Fe, $75 \mathrm{mg}$; Mn, $35 \mathrm{mg}$; Cu, $5 \mathrm{mg}$ $\mathrm{Zn}, 75 \mathrm{mg}$; I, $1.75 \mathrm{mg}$; Co, $2 \mathrm{mg}$; and Se, $0.2 \mathrm{mg}$.

$\ddagger$ Calculated by subtracting the IDF content from the TDF content.

$\S$ Derived by subtracting the crude protein, crude fat, starch and sugar content from the organic matter content ${ }^{(17)}$. As inulin was included in the analysed sugar content, the NSP content of the HFF diet is underestimated with approximately $18 \mathrm{~g} / \mathrm{kg} \mathrm{DM}(20 \mathrm{~g} / \mathrm{kg}$ included in the diet with $90 \%$ pure inulin). 
(NDF), acid-detergent fibre (ADF), acid-detergent lignin and Ti. $\mathrm{DM}$ and ash contents were determined by drying to a constant weight at $103^{\circ} \mathrm{C}$ and combustion at $550^{\circ} \mathrm{C}$, respectively. The starch content was analysed enzymatically ${ }^{(24)}$, while reducing sugars were extracted from the feed samples using $40 \%$ ethanol and determined as described by Suárez et al. ${ }^{(25)}$. Crude protein $(6.25 \times \mathrm{N})$ was determined using the Kjeldahl method (ISO 5983-1, 2005) and crude fat was analysed according to the Berntop method (ISO 6492, 1999) with faecal samples being pre-digested with $\mathrm{HCl}$. TDF and insoluble dietary fibre were analysed using the Association of Official Analytical Chemists methods ${ }^{(26,27)}$. The soluble dietary fibre content was calculated by subtracting the insoluble dietary fibre content from the TDF content. Note that the inulin would not be recovered in the TDF fraction ${ }^{(28)}$. NDF was analysed in defatted diet samples (fat extraction with petroleumether) according to a modified method of Van Soest et al. ${ }^{(29)}$ described by Goelema et al. ${ }^{(30)}$. The ADF and acid-detergent lignin contents were determined according to Van Soest ${ }^{(31)}$. Ti was analysed using a modified method based on the work by Short et al. ${ }^{(32)}$ and Myers et al. ${ }^{(33)}$. The content of NSP was calculated by subtracting the starch, sugar, crude protein and crude fat content from the organic matter content ${ }^{(17)}$. As inulin was included in the analysed sugar content, the NSP content of the HFF diet is underestimated with approximately $18 \mathrm{~g} / \mathrm{kg} \mathrm{DM}(20 \mathrm{~g} / \mathrm{kg}$ included in the diet with $90 \%$ pure inulin).

\section{Apparent digestibility}

After $10 \mathrm{~d}$ of adaptation to the experimental diets, a $3 \mathrm{~d}$ faecal collection was conducted for the determination of apparent digestibility of nutrients. On these days, all faeces produced by each dog were collected twice a day and weighed. The faeces were freeze-dried to a constant weight, pooled per dog and ground over a $1 \mathrm{~mm}$ sieve in a Retsch mill (ZM100, Retsch B.V., Ochten, The Netherlands). Then the faeces of each dog were analysed for DM, ash, crude protein, crude fat, NDF, ADF, acid-detergent lignin and Ti, according to the procedures described previously. Starch and sugar were not analysed as these were assumed to be completely digested and absorbed. The NSP content of faeces was calculated by subtracting the crude protein and fat contents from the organic matter content. The apparent digestibility coefficient (ADC) for the nutrients was calculated using the following equations:

$$
\begin{gathered}
\text { Nutrient }_{\text {flow }}=\text { Nutrient }_{f} \times \frac{\mathrm{Ti}_{i}}{\mathrm{Ti}_{f}}, \\
\operatorname{ADC}(\%)=\frac{\text { Nutrient }_{i}-\text { Nutrient }_{\text {flow }}}{\text { Nutrient }_{i}} \times 100 \%,
\end{gathered}
$$

where Nutrient flow $_{\text {is }}$ ise nutrient flow $(\mathrm{g} / \mathrm{d})$, Nutrient , $_{f}$ is the nutrient content of faeces $(\mathrm{g} / \mathrm{kg} \mathrm{DM}), \mathrm{Ti}_{i}$ is the $\mathrm{Ti}$ intake $(\mathrm{g}), \mathrm{Ti}_{f}$ is the $\mathrm{Ti}$ content of faeces $(\mathrm{g} / \mathrm{kg} \mathrm{DM})$ and Nutrient ${ }_{i}$ is the nutrient intake $(\mathrm{g} / \mathrm{d})$.

\section{Faecal consistency and fermentation products}

To evaluate colonic microbial fermentative activity for both dietary treatment groups, fresh faeces were collected from each dog during week 5 of the experiment within 15 min of defecation. Faeces consistency was scored using the following system $^{(34)}: 1=$ hard, dry pellets - small, hard mass; $2=$ hard, formed, dry stool - remains firm and soft; $3=$ soft, formed moist - softer stool that retains shape; $4=$ soft, unformed stool assumes shape of container; $5=$ watery - liquid that can be poured. Directly after faecal scoring, the faeces were collected and homogenised using two spoons whereafter the samples were taken for SCFA, $\mathrm{NH}_{3}$ and DM contents. All materials used for faeces collection and sampling were pre-sterilised using $70 \%$ ethanol. For the determination of faecal SCFA and $\mathrm{NH}_{3}$ content, a sample of approximately $0.5-1.0 \mathrm{~g}$ was added to a $2 \mathrm{ml}$ safe-lock tube (Eppendorf AG, Hamburg, Germany) containing $1.0 \mathrm{ml}$ of $0.033 \mathrm{M}-\mathrm{H}_{3} \mathrm{PO}_{4}$ for SCFA analysis or $1.0 \mathrm{ml}$ of $10 \%$ TCA for $\mathrm{NH}_{3}$ analysis. After the addition of faeces, the contents of each tube were mixed on a vortex for $3 \mathrm{~s}$, weighed and stored at $-20^{\circ} \mathrm{C}$. For DM determination, approximately $1.5 \mathrm{~g}$ of faeces was added to a pre-weighed $2 \mathrm{ml}$ safe-lock tube (Eppendorf AG), weighed and stored at $-20^{\circ} \mathrm{C}$. For the determination of SCFA and $\mathrm{NH}_{3}$, the samples were thawed, mixed and centrifuged at $15000 \mathrm{rpm}$ for $5 \mathrm{~min}$ at $4^{\circ} \mathrm{C}$ (Centrifuge 5417R, Eppendorf AG). Concentrations of the SCFA (i.e. acetate, propionate, butyrate, iso-butyrate, valerate, iso-valerate) in the supernatant were determined as described by Bosch et al. ${ }^{(21)}$ Branched-chain proportion was calculated as the percentage of branched-chain fatty acids (iso-butyrate, valerate, iso-valerate) of total $\mathrm{SCFA}^{(35)}$. The faecal DM content was determined by freeze-drying to constant weight and used to calculate SCFA and $\mathrm{NH}_{3}$ content in the original faeces.

\section{Blood sampling and plasma analyses}

Blood sampling was performed in week 6 of the experiment. The dogs were sedated using $0.02 \mathrm{ml} / \mathrm{kg}$ BW methadone hydrochloride (Mephenon ${ }^{\circledR}$, Denolin, Brussels, Belgium) and a central venous catheter $\left(18 \mathrm{G} / 20 \mathrm{~cm}\right.$ Leaderflex ${ }^{\circledR}$; Vygon, Écouen, France) was placed in the jugular vein. The catheters were flushed with $1 \mathrm{ml}$ heparinised saline $(0 \cdot 1 \mathrm{mg}$ heparin $/ \mathrm{ml}$ saline solution) directly after catheter placement and just before the sampling procedure. Furthermore, at the time of placement of the catheter, $15 \mathrm{mg} / \mathrm{kg} \mathrm{BW}$ amoxicillin (Clamoxyl LA ${ }^{\circledR}$, GlaxoSmithKline N.V., Genval, Belgium) was administered subcutaneously. Blood samples $(2.5-3.0 \mathrm{ml})$ were obtained from each dog $30 \mathrm{~min}$ prior to feeding and 20, 40, 60 and $90 \mathrm{~min}$ postprandial. Thereafter, blood was sampled from four dogs in each group at 120, 180, 240, $300,360,420,480$ and $540 \mathrm{~min}$ after feeding, while the other four dogs in each group were sampled at 150, 210, $270,330,390,450,510$ and $570 \mathrm{~min}$ after feeding. The blood samples were collected in chilled collection tubes containing $\mathrm{K}_{3}$ EDTA as an anticoagulant. After gentle mixing of the contents, each collection tube was opened and $25 \mu 1$ dipeptidyl peptidase-IV inhibitor (Linco Research, MI, USA) and $125 \mu \mathrm{l} \mathrm{Trasylol}{ }^{\circledR}(1.4 \mathrm{mg}$ aprotinin/ml, Bayer AG, Leverkusen, Germany) were added. After gentle mixing of the contents, the tubes were temporarily stored on ice until centrifugation at $2500 \mathrm{~g}$ for $15 \mathrm{~min}$ at $4^{\circ} \mathrm{C}$. After centrifugation, plasma was removed and stored in safe-lock tubes (Eppendorf AG) at $-20^{\circ} \mathrm{C}$ until analysis. Each blood sample was processed within $30 \mathrm{~min}$ after collection. Blood plasma was analysed for glucose, insulin, total PYY, total GLP-1 
and total ghrelin concentration. Plasma glucose was analysed according to the hexokinase method using a commercial test kit (Human GmbH, Wiesbaden, Germany), while plasma insulin, total PYY and total ghrelin were analysed using commercial RIA kits (human-specific insulin RIA kit, Linco Research; rat/mouse PYY RIA kit, Linco Research; and total ghrelin RIA kit, Linco Research, respectively). Plasma GLP-1 was analysed using an RIA specific for the C-terminal of the amidated GLP-1 ${ }^{(36,37)}$. The intra-assay $\mathrm{CV}$ for the assays were $7 \cdot 1 \%$ for insulin, $6.2 \%$ for ghrelin, $14.8 \%$ for PYY and $6 \%$ for GLP-1. The values obtained at 120 and 150, 180 and 210, 240 and 270, 300 and 330, 360 and 390, 420 and 450, and 480 and $540 \mathrm{~min}$ postprandial were analysed together and are presented as time points 135, 195, 255, 315, 375, 435 and $495 \mathrm{~min}$, respectively. The basal concentration was defined as the average of the level in the first and last samples (30 min before the morning feeding and $45 \mathrm{~min}$ before the evening feeding, respectively). For PYY, GLP-1 and ghrelin, the area under the curve (AUC) from basal until 195 min after the meal and the AUC from 195 to 495 min after the meal for each measured parameter were approximated using the trapezoidal summation. Trapezoids were calculated as the length of the base (interval time between consecutive samples in min) times the average of the heights of the two sides (concentrations of consecutive samples). The time intervals were selected based on a minimal orocaecal transit time of approximately $2.7 \mathrm{~h}$ in Standard Schnauzers with a BW of 12.9 (SEM $2 \cdot 1) \mathrm{kg}^{(38)}$. From this time onwards, the digesta arrives in the large intestine and fermentable dietary fibre becomes available for the microbial population and SCFA may be produced.

\section{Voluntary food intake}

At the end of the study (week 7), each dog was offered $1 \mathrm{~kg}$ of the dry extruded control diet that dogs previously experienced as palatable (Hill's Science Plan Canine Adult with Beef, Hill's Pet Nutrition Inc., Topeka, KS, USA). The dogs were allowed to eat for $20 \mathrm{~min}$, after which food intake was recorded. The diet was offered to each dog at precisely $6 \mathrm{~h}$ after the morning feeding (14.30 hours).

\section{Statistical analyses}

The dogs were randomly allocated to the two treatments according to the BW and sex. All data were analysed using the Statistical Analysis Systems statistical software package version 9.1 (SAS Institute, Cary, NC, USA). Differences in the ADC of nutrients, faecal characteristics (faecal score, DM, SCFA and $\mathrm{NH}_{3}$ ) and plasma metabolites (the basal concentrations of glucose, insulin, PYY, GLP-1 and ghrelin and AUC (0-195 and 195-495 min) of PYY, GLP-1 and ghrelin) between the dietary treatment groups were tested for significance using ANOVA by Proc GLM. The model used was $Y=\mu+D_{i}+\varepsilon_{i j}$, where $Y$ is the dependent variable, $\mu$ is the average intercept, $D_{i}$ is the effect of diet $i$ and $\varepsilon_{i j}$ is the error term. For the VFI data, BW loss (as the percentage of initial BW) tended to be significant $(P=0.098)$ and was therefore included in the statistical model as a covariate. The effects of diet and time after feeding on plasma glucose, insulin, PYY, GLP-1 and ghrelin were tested for significance using ANOVA by Proc MIXED. The statistical model was
$Y=\mu+D_{i}+T_{j}+(D \times T)_{i j}+\varepsilon_{i j k}$, where $Y$ is the dependent variable, $\mu$ is the average intercept, $D_{i}$ is the effect of diet $i, T_{j}$ is the effect of time $j,(D \times T)_{i j}$ is the interaction between diet and time and $\varepsilon_{i j k}$ is the error term. The basal concentrations were significant $(P<0 \cdot 010)$ and included in the model as covariate. The correlations between VFI and plasma glucose and hormone concentrations were calculated using the Proc CORR statement. Differences were considered to be significant at $P \leq 0.05$.

\section{Results}

All dogs remained healthy throughout the study, although a general decrease in the BW was observed for both groups (approximately $5 \% \mathrm{BW}$ loss for each dietary treatment). No significant differences were found between the dietary treatments in the $\mathrm{BW}$ at the start and end of the experiment and BW loss $(P=0.906,0.909$ and 0.927 , respectively; data not shown). One dog in the LFF treatment group lost substantial BW during the trial and showed very high concentrations of ghrelin compared with the other dogs. The obtained physiological and VFI data from this dog were therefore excluded from the statistical analyses.

\section{Apparent digestibility}

The dogs fed the HFF diet showed higher ADC for DM and organic matter $(P<0 \cdot 001)$, whereas the LFF-fed dogs had a higher ADC for crude fat $(P<0.001)$ and tended to have a higher crude protein digestibility $(P=0.099$; Table 2$)$. The NSP digestibility was higher for the HFF diet compared with the LFF diet $(P<0 \cdot 001)$. In addition, the dogs fed the HFF diet showed higher ADC for NDF $(P<0.001)$ and ADF $(P=0.002)$ and tended to have a lower ADC for acid-detergent lignin $(P=0 \cdot 082)$ compared with the dogs fed the LFF diet. Finally, the ADC for energy was higher for the HFF-fed dogs compared with the LFF-fed dogs $(P<0 \cdot 001)$.

Table 2. Apparent digestibility coefficient (ADC; \%) for nutrients and energy in the low-fermentable fibre diet (LFF) or the high-fermentable diet (HFF) fed to dogs

(Mean values with their standard errors for eight LFF-fed dogs and eight HFF-fed dogs)

\begin{tabular}{lrrrrrr}
\hline & \multicolumn{2}{c}{ LFF } & & \multicolumn{2}{c}{ HFF } \\
\cline { 2 - 3 } \cline { 5 - 6 } & Mean & SEM & & Mean & SEM & \multicolumn{1}{c}{$P$} \\
\hline DM & 77.9 & 0.28 & 80.9 & 0.56 & $<0.001$ \\
OM & 80.6 & 0.25 & 84.1 & 0.57 & $<0.001$ \\
Crude protein & 77.3 & 0.81 & 75.4 & 0.68 & 0.099 \\
Crude fat* & 94.5 & 0.19 & 92.3 & 0.18 & $<0.001$ \\
NDF & 37.0 & 0.59 & 62.3 & 2.14 & $<0.001$ \\
ADF & 3.3 & 0.96 & 22.3 & 5.00 & 0.002 \\
ADL & 43.7 & 4.13 & 34.9 & 2.26 & 0.082 \\
NSP & -2.8 & 0.69 & 20.6 & 4.96 & $<0.001$ \\
Gross energy & 82.7 & 0.25 & 84.9 & 0.43 & $<0.001$ \\
\hline
\end{tabular}

OM, organic matter; NDF, neutral-detergent fibre; ADF, acid-detergent fibre; ADL, acid-detergent lignin.

* Due to the limited amount of faecal material available for the analysis, the values presented were based on seven dogs for the LFF treatment and six dogs for the HFF treatment. 


\section{Faecal consistency and fermentation products}

Significant differences in the faecal characteristics between the treatment groups were observed (Table 3). The faecal DM content was lower for the dogs fed the HFF than the LFF $(P<0.001)$ diet. Compared with the dogs fed the LFF diet, higher total SCFA, acetate and propionate concentrations were found for the dogs fed the HFF diet $(P<0 \cdot 001)$. Moreover, butyrate concentrations tended to be higher in the HFF dogs $(P=0.060)$. The dogs fed the LFF diet showed a higher branched-chain ratio and $\mathrm{NH}_{3}$ concentration in the faeces compared with the dogs fed the HFF diet $(P=0.002$ and 0.009 , respectively). No treatment effect was found for faecal consistency score $(P=0 \cdot 590)$.

\section{Plasma metabolites}

Plasma glucose, insulin, PYY, GLP-1 and ghrelin parameters for both the dietary groups are shown in Table 4 . The basal concentrations of the measured metabolites were not different between the treatments groups $(P>0 \cdot 05)$. For all the measured metabolites, postprandial concentrations changed after the meal $(P<0 \cdot 01)$, but the concentrations were not affected by the dietary treatment $(P>0 \cdot 10$ for diet and diet $\times$ time interaction, data not shown). No significant differences were found between the treatment groups in $\mathrm{AUC}_{0-195 \mathrm{~min}}$ and $\mathrm{AUC}_{195-495 \mathrm{~min}}$ of PYY, GLP-1 and ghrelin $(P>0 \cdot 10)$.

\section{Voluntary food intake}

For each dog, the amount of food consumed at the end of the study was lower than the amount of food offered. The dogs fed the HFF diet tended to show a lower VFI compared with the dogs fed the LFF diet $(P=0 \cdot 058$, Fig. 1). No significant correlations were found between VFI and glucose, insulin, PYY, GLP-1 or ghrelin concentration in plasma at $6 \mathrm{~h}$ after the meal $(P>0 \cdot 05$, data not shown).

\section{Discussion}

The present study evaluated the impact of dietary fibre fermentability on the duration of postprandial satiety as measured by the hormones involved in satiation and VFI in dogs.

Table 3. Characteristics of the faeces of the dogs fed the low-fermentable fibre (LFF) diet and the high-fermentable (HFF) diet

(Mean values with their standard errors for eight LFF-fed dogs and eight HFF-fed dogs)

\begin{tabular}{|c|c|c|c|c|c|}
\hline & \multicolumn{2}{|c|}{ LFF } & \multicolumn{2}{|c|}{ HFF } & \multirow[b]{2}{*}{$P$} \\
\hline & Mean & SEM & Mean & SEM & \\
\hline $\mathrm{DM}(\mathrm{g} / \mathrm{kg})$ & $379 \cdot 1$ & $15 \cdot 5$ & $231 \cdot 0$ & 9.5 & $<0.001$ \\
\hline Total SCFA (mmol/g DM) & 0.26 & 0.02 & 0.54 & 0.04 & $<0.001$ \\
\hline Acetate $(\mathrm{mmol} / \mathrm{g} \mathrm{DM})$ & 0.14 & 0.02 & 0.32 & 0.03 & $<0.001$ \\
\hline Propionate (mmol/g DM) & 0.06 & 0.01 & 0.14 & 0.01 & $<0.001$ \\
\hline Butyrate (mmol/g DM) & 0.03 & 0.00 & 0.05 & 0.01 & 0.060 \\
\hline $\mathrm{BCP}(\%)^{*}$ & $8 \cdot 51$ & 0.87 & $4 \cdot 40$ & 0.68 & 0.002 \\
\hline $\mathrm{NH}_{3}(\mathrm{mg} / \mathrm{g} \mathrm{DM})$ & 2.73 & 0.24 & $3 \cdot 45$ & 0.53 & 0.240 \\
\hline $\mathrm{NH}_{3}(\mathrm{mg} / \mathrm{ml}$ faecal water $)$ & $1 \cdot 66$ & $0 \cdot 15$ & 1.02 & 0.15 & 0.009 \\
\hline Faecal score $(1-5)$ & 2.44 & $0 \cdot 11$ & $2 \cdot 50$ & 0.00 & 0.590 \\
\hline
\end{tabular}

$\mathrm{BCP}$, branched-chain proportion.

${ }^{*}$ Calculated as the percentage of branched-chain fatty acids (iso-butyrate, valerate, iso-valerate) of total SCFA ${ }^{(35)}$
Table 4. Plasma glucose, insulin, peptide tyrosine-tyrosine (PYY), glucagon-like peptide-1 (GLP-1) and ghrelin parameters in the dogs fed a low-fermentable fibre diet (LFF) or a high-fermentable fibre diet (HFF)

(Least-squares means with their standard errors for seven LFF-fed dogs and eight HFF-fed dogs)

\begin{tabular}{|c|c|c|c|c|c|}
\hline & \multicolumn{2}{|c|}{ LFF } & \multicolumn{2}{|c|}{ HFF } & \multirow[b]{2}{*}{$P$} \\
\hline & Mean & SEM & Mean & SEM & \\
\hline \multicolumn{6}{|l|}{ Basal concentration } \\
\hline Glucose (mmol/l) & $5 \cdot 6$ & 0.2 & $5 \cdot 8$ & $0 \cdot 2$ & 0.481 \\
\hline Insulin ( $\mu U / m l)$ & $10 \cdot 5$ & $1 \cdot 8$ & $10 \cdot 2$ & $1 \cdot 7$ & 0.918 \\
\hline PYY (pg/ml) & 954 & 79 & 993 & 79 & 0.734 \\
\hline GLP-1 (pmol/l) & $18 \cdot 6$ & $2 \cdot 3$ & $23 \cdot 1$ & 1.9 & 0.164 \\
\hline Ghrelin (pg/ml) & 2308 & 492 & 2900 & 461 & 0.396 \\
\hline \multicolumn{6}{|l|}{$\mathrm{AUC}_{0-195 \mathrm{~min}}$} \\
\hline PYY ((pg/ml)/min) & 1114 & 56 & 1117 & 56 & 0.977 \\
\hline GLP-1 ((pmol/l)/min) & $26 \cdot 4$ & $3 \cdot 3$ & $25 \cdot 8$ & $2 \cdot 8$ & 0.885 \\
\hline Ghrelin $((p g / m l) / m i n)$ & 1852 & 338 & 2094 & 293 & 0.599 \\
\hline \multicolumn{6}{|l|}{$\mathrm{AUC}_{195-495 \mathrm{~min}}$} \\
\hline PYY ((pg/ml)/min) & 1060 & 47 & 1074 & 47 & 0.833 \\
\hline GLP-1 ((pmol/l)/min) & $24 \cdot 4$ & 1.9 & $25 \cdot 6$ & 1.8 & 0.681 \\
\hline Ghrelin $((\mathrm{pg} / \mathrm{ml}) / \mathrm{min})$ & 2200 & 473 & 2657 & 410 & 0.479 \\
\hline
\end{tabular}

AUC, area under the curve.

The selection of fibre sources was based on the in vitro fermentation studies ${ }^{(21,22)}$, that showed a low microbial degradability for cellulose and moderate and rapid fermentability for, respectively, sugarbeet pulp and inulin using the faeces from the dogs as inoculate. The difference in fibre degradability between the two diets was also shown in the present study. The dogs fed the HFF diet showed a higher ADC for NDF, ADF and NSP compared with the LFF-fed dogs, indicating a higher intestinal microbial degradability of those fibre sources used in the HFF diet. The higher microbial fibre degradation in the HFF-fed dogs resulted in a higher SCFA production, also reflected in a higher SCFA concentration in the faeces of these dogs. In the case of low availability of fermentable fibre (as with the LFF diet), the microbial population

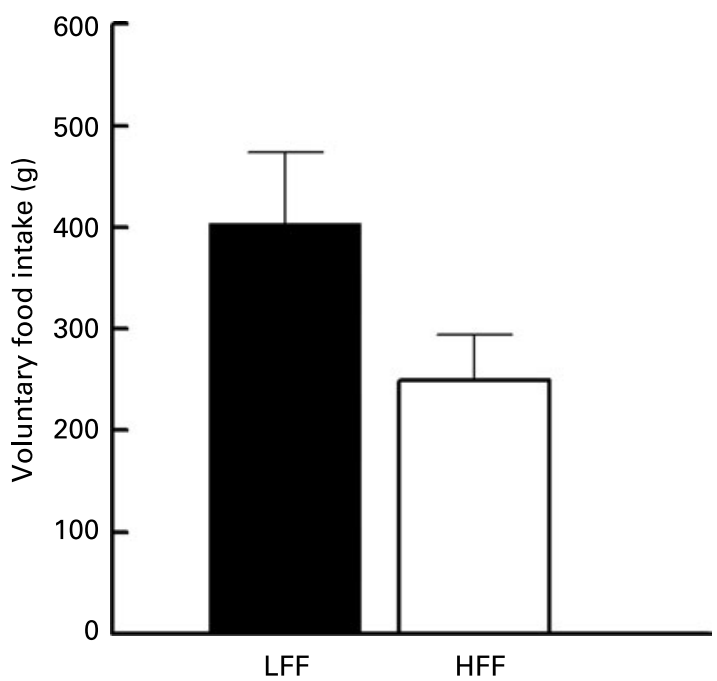

Fig. 1. Voluntary food intake of the low-fermentable fibre (LFF) and high-fermentable diet (HFF)-fed dogs. Dogs had ad libitum access for $20 \mathrm{~min}$ to the control diet that was presented $6 \mathrm{~h}$ following their morning meal (experimental diet). Values are means for seven dogs fed the LFF and eight dogs fed the HFF, with their standard errors represented by vertical bars $(P=0.058)$. 
will probably resort to more proteolytic fermentation ${ }^{(39)}$. This was observed in the present study where the LFF-fed dogs showed a higher faecal $\mathrm{NH}_{3}$ concentration and BCP, both being the indicators of microbial protein degradation ${ }^{(40)}$. Finally, the ADC for crude protein tended to be lower for the dogs on the HFF diet, which is in agreement with the similar studies evaluating fermentable dietary sources ${ }^{(20,41,42)}$. It is suggested that this decrease should not be attributed to a lower true protein digestibility ${ }^{(41)}$, but is related to an increased microbial proliferation and to a higher faecal bacterial protein excretion $^{(20,42)}$. From these summarised results, it can be concluded that compared with the LFF diet, the HFF diet resulted in higher large intestinal dietary fibre fermentation. This would consequently lead to higher SCFA concentrations in the large intestine.

The increased large intestinal fermentation was expected to have an impact on host satiety and appetite through its effect on the secretion of the gastrointestinal satiety-related hormones PYY, GLP-1 and ghrelin. Concerning the feelings of satiety and appetite, the dogs in the HFF treatment group tended to have a lower VFI compared with the LFF-fed dogs $(P=0.058)$. This suggests that dogs fed the HFF diet were less motivated to consume food when freely available. The amount of food consumed was however not correlated with any of the measured physiological metabolites. The causal relationship between the postprandial satiety-related hormone concentrations and the feelings of satiety or hunger varies between studies. For example, several recent studies found an association in the human subjects of changes in self-reported hunger or satiety after a test meal with changes in the concentrations of postprandial PYY ${ }^{(43,44)}$, whereas Weickert et al. ${ }^{(45)}$ reported blunted postprandial PYY and ghrelin responses in healthy women without alterations in hunger scores. Furthermore, Smeets et al. ${ }^{(46)}$ found that a high-protein lunch increased satiety but without increasing the plasma GLP-1 response, whereas a lunch adequate in protein but with a high carbohydrate content resulted in lower satiety rating but with increased GLP-1 response. Based on these findings, it was therefore suggested that the concentrations in the satiety-related hormones may be related to the nutrient-induced satiety without being directly and mathematically related to satiety ${ }^{(47)}$. This relationship may also indicate differences in interactions with other hormones or central sensitivity for these hormones ${ }^{(46)}$.

It can be questioned whether the dietary contrasts in the present study were sufficient to evoke differences in the secretion of measured hormones. The HFF contained $85 \mathrm{~g} / \mathrm{kg}$ as-fed sugarbeet pulp and $20 \mathrm{~g} / \mathrm{kg}$ as-fed inulin which was slightly higher compared with the HFF diet used by Massimino et al. ${ }^{(11)}(60 \mathrm{~g} / \mathrm{kg}$ sugarbeet pulp, $20 \mathrm{~g} / \mathrm{kg}$ gum arabic, $15 \mathrm{~g} / \mathrm{kg}$ fructo-oligosaccharide on as-fed basis). The dogs fed the latter diet showed enhanced GLP-1 production and plasma GLP-1 concentrations after an oral load of glucose compared with the dogs fed a diet containing $70 \mathrm{~g} / \mathrm{kg}$ as-fed cellulose $^{(11)}$. The dietary contrast in the present experiment can therefore be considered to have the potential to affect at least GLP-1 production and secretion.

The present study aimed to induce a contrast in large intestinal SCFA concentrations that would affect the secretion of PYY and GLP-1 by the enteroendocrine L-cells. These specialised cells are present predominantly in the canine distal gastrointestinal tract ${ }^{(48)}$. It has been suggested that SCFA (mainly acetate and propionate) activate the GPR43 receptor expressed by the L-cells that are consequently stimulated to release $\mathrm{PYY}^{(49)}$. Several studies reported increased PYY release after the large intestinal infusion of SCFA in rats ${ }^{(7)}$ and oleic acid in $\operatorname{dog} s^{(8)}$. In addition, inclusion of fermentable fibre in a diet increased large intestinal PYY gene expression $^{(50)}$ and PYY concentrations in rats ${ }^{(50,51)}$. Gee \& Johnson $^{(52)}$ reported similar effects of a single meal of fermentable fibre on plasma PYY concentrations in rats, but in the human subjects the observed effects were less. In addition to the production of PYY, the L-cells produce GLP-1 derived from the precursor molecule proglucagon ${ }^{(10)}$. Several studies reported enhanced expression of the proglucagon gene by $\mathrm{SCFA}^{(53)}$ or inclusion of fermentable fibre in the $\operatorname{diet}^{(11,50)}$ Moreover, fermentable fibre increased the number of L-cells in the proximal colon of rats ${ }^{(54)}$. On the other hand, GLP-1 release was not stimulated after large intestinal SCFA infusion in rats $^{(7)}$. Interactions between satiety-related hormones may have contributed to the observed effects on satiety. For example, Neary et al. ${ }^{(55)}$ observed additive effects of PYY and GLP-1 in the inhibition of appetite and induction of satiety. Similarly, in obese rats a combination of intraperitoneal injection of amylin and PYY was found to reduce food intake more than amylin or PYY alone ${ }^{(56)}$.

Other mechanisms underlying the feelings of satiety or hunger may also have contributed to the observed differences between the treatment groups. Although for both experimental diets postprandial glucose concentrations were equally stable and no large fall below basal glucose level was found in sows as observed by de Leeuw et al. ${ }^{(17)}$, small transient declines in blood glucose concentrations could still be present and different between treatments. A transient decline in blood glucose preceded meal initiation in rats ${ }^{(57)}$ and a meal request in the human subjects ${ }^{(58)}$. Similar observations could only be performed when blood was sampled more frequently for glucose determination or continuous monitoring of blood glucose concentrations. Furthermore, the SCFA mainly produced in the HFF-fed dogs can be used as a source of energy (mainly acetate) at times when glucose supply from the small intestine is decreasing ${ }^{(59,60)}$. Bleiberg et al. ${ }^{(60)}$ estimated that large intestinal acetate production could contribute in excess of $5 \%$ of the total energy needs of dogs. Whether the SCFA from large intestinal fermentation and used as a source of energy will lead to pronounced differences in the feelings of satiety remains to be investigated.

In conclusion, the present study showed that the dogs fed the HFF diet had an increased large intestinal fibre degradation and the production of SCFA than the dogs fed the LFF diet. The HFF-fed dogs consumed less food during a challenge meal, which may be related to increased feelings of satiety. Postprandial plasma PYY, GLP-1, ghrelin and glucose responses did not differ between the treatment groups and could not be linked to the observed lowered voluntary food consumption of the dogs fed the HFF diet. It is likely that other satiety-related hormones and/or mechanisms controlling the feelings of satiety or hunger may have been involved in the observed decrease in VFI in the present study. Finally, inclusion of fermentable fibre in canine diets may contribute to the prevention or mitigation of obesity through its effects on satiety. 


\section{Acknowledgements}

The present study was supported by the Wageningen Institute of Animal Sciences and the Laboratory of Animal Nutrition, Ghent University. George Fahey Jr is acknowledged for his advices concerning the composition of the experimental diets. The authors sincerely thank Steven Galle, Rebekka Hollebosch, Mariëtte Kooper, Yvonne Paijmans, Georgios Papadopoulos and Herman De Rycke involved in the caretaking of the dogs and/or sample collection. All authors contributed fundamentally to the present study. G. B. contributed to all facets including research design, data collection, analyses, interpretation and manuscript preparation; W. H. H., M. H., G. P. J. J. and A. F. B. v. d. P. contributed to research design, data interpretation and manuscript preparation; A. V. and M. H. contributed to animal expertise, blood-collection protocol, blood collection and manuscript preparation; J. J. H. contributed to GLP-1 analyses, data interpretation and manuscript preparation. The authors declare that there is no conflict of interest.

\section{References}

1. German AJ (2006) The growing problem of obesity in dogs and cats. J Nutr 136, S1940-S1946.

2. McGreevy PD, Thomson PC, Pride C, et al. (2005) Prevalence of obesity in dogs examined by Australian veterinary practices and the risk factors involved. Vet Rec 156, 695-702.

3. Weber M, Bissot T, Servet E, et al. (2007) A high-protein, highfiber diet designed for weight loss improves satiety in dogs. $J$ Vet Intern Med 21, 1203-1208.

4. Jewell DE \& Toll PW (1996) Effects of fiber on food intake in dogs. Vet Clin Nutr 3, 115-118.

5. Jackson JR, Laflamme DP \& Owens SF (1997) Effects of dietary fiber content on satiety in dogs. Vet Clin Nutr 4, 130-134.

6. Butterwick RF \& Markwell PJ (1997) Effect of amount and type of dietary fiber on food intake in energy-restricted dogs. Am J Vet Res 58, 272-276.

7. Anini Y, Fu-Cheng X, Cuber JC, et al. (1999) Comparison of the postprandial release of peptide $\mathrm{YY}$ and proglucagon-derived peptides in the rat. Pflügers Arch 438, 299-306.

8. Greeley GH Jr, Hashimoto T, Izukura M, et al. (1989) A comparison of intraduodenally and intracolonically administered nutrients on the release of peptide-YY in the dog. Endocrinology 125, 1761-1765.

9. Batterham RL, Cowley MA, Small CJ, et al. (2002) Gut hormone PYY(3-36) physiologically inhibits food intake. Nature 418, 650-654.

10. Holst JJ (2007) The physiology of glucagon-like peptide 1 . Physiol Rev 87, 1409-1439.

11. Massimino SP, McBurney MI, Field CJ, et al. (1998) Fermentable dietary fiber increases GLP-1 secretion and improves glucose homeostasis despite increased intestinal glucose transport capacity in healthy dogs. J Nutr 128, 1786-1793.

12. Wen J, Phillips SF, Sarr MG, et al. (1995) PYY and GLP-1 contribute to feedback inhibition from the canine ileum and colon. Am J Physiol Gastrointest Liver Physiol 269, G945-G952.

13. Pappas TN, Melendez RL \& Debas HT (1989) Gastric distension is a physiologic satiety signal in the dog. Dig Dis Sci $\mathbf{3 4}$, 1489-1493.

14. Houpt KA (1982) Gastrointestinal factors in hunger and satiety. Neurosci Biobehav Rev 6, 145-164.

15. Holt S, Heading RC, Carter DC, et al. (1979) Effect of gel fibre on gastric emptying and absorption of glucose and paracetamol. Lancet i, 636-639.
16. Roberfroid M (1993) Dietary fiber, inulin, and oligofructose: a review comparing their physiological effects. Crit Rev Food Sci Nutr 33, 103-148.

17. de Leeuw JA, Jongbloed AW \& Verstegen MWA (2004) Dietary fiber stabilizes blood glucose and insulin levels and reduces physical activity in sows (Sus scrofa). J Nutr 134, 1481-1486.

18. Cummings DE, Purnell JQ, Frayo RS, et al. (2001) A preprandial rise in plasma ghrelin levels suggests a role in meal initiation in humans. Diabetes 50, 1714-1719.

19. Cani PD, Dewever C \& Delzenne NM (2004) Inulin-type fructans modulate gastrointestinal peptides involved in appetite regulation (glucagon-like peptide-1 and ghrelin) in rats. $\mathrm{Br} J$ Nutr 92, 521-526.

20. Hesta M, Roosen W, Janssens GP, et al. (2003) Prebiotics affect nutrient digestibility but not faecal ammonia in dogs fed increased dietary protein levels. Br J Nutr 90, 1007-1014.

21. Bosch G, Pellikaan WF, Rutten PGP, et al. (2008) Comparative in vitro fermentation activity in the canine distal gastrointestinal tract and fermentation kinetics of fiber sources. J Anim Sci 86, 2979-2989.

22. Sunvold GD, Fahey GC Jr, Merchen NR, et al. (1995) Dietary fiber for dogs: IV. In vitro fermentation of selected fiber sources by dog fecal inoculum and in vivo digestion and metabolism of fiber-supplemented diets. J Anim Sci 73, 1099-1109.

23. Jagger S, Wiseman J, Cole DJ, et al. (1992) Evaluation of inert markers for the determination of ileal and faecal apparent digestibility values in the pig. Br J Nutr 68, 729-739.

24. Brunt K (1993) Enzymatic determination of starch content in feed and feedstuffs, Memo 93-302, (in Dutch) Groningen: Stichting Nederlands Instituut voor Koolhydraat Onderzoek.

25. Suárez BJ, Van Reenen CG, Beldman G, et al. (2006) Effects of supplementing concentrates differing in carbohydrate composition in veal calf diets: I. Animal performance and rumen fermentation characteristics. J Dairy Sci 89, 4365-4375.

26. AOAC (1995) AOAC Method 985.29. Total dietary fiber in foods: enzymatic-gravimetric method. In Official Methods of Analysis, 16th ed. [P Cunniff, editor]. Washington, DC: Association of Official Analytical Chemists.

27. AOAC (1995) AOAC Method 991.42. Insoluble dietary fiber in foods and food products: enzymatic-gravimetric method, phosphate buffer. In Official Methods of Analysis, 16th ed. [P Cunniff, editor]. Washington, DC: Association of Official Analytical Chemists.

28. Prosky L \& Hoebregs H (1999) Methods to determine food inulin and oligofructose. $J$ Nutr 129, S1418-S1423.

29. Van Soest PJ, Robertson JB \& Lewis BA (1991) Methods for dietary fibre, neutral detergent fibre, and nonstarch polysaccharides in relation to animal nutrition. J Dairy Sci 74, 3583-3597.

30. Goelema JO, Spreeuwenberg MAM, Hof G, et al. (1998) Effect of pressure toasting on the rumen degradability and intestinal digestibility of whole and broken peas, lupins and faba beans and a mixture of these feedstuffs. Anim Feed Sci Technol 76, 35-50.

31. Van Soest PJ (1973) Collaborative study of acid-detergent fibre and lignin. J Assoc Off Anal Chem 56, 781-784.

32. Short FJ, Gorton P, Wiseman J, et al. (1996) Determination of titanium dioxide added as an inert marker in chicken digestibility studies. Anim Feed Sci Technol 59, 215-221.

33. Myers WD, Ludden PA, Nayigihugu V, et al. (2004) Technical note: a procedure for the preparation and quantitative analysis of samples for titanium dioxide. J Anim Sci 82, 179-183.

34. Middelbos IS, Fastinger ND \& Fahey GC Jr (2007) Evaluation of fermentable oligosaccharides in diets fed to dogs in comparison to fiber standards. J Anim Sci 85, 3033-3044.

35. Awati A, Williams BA, Bosch MW, et al. (2006) Use of the in vitro cumulative gas production technique for pigs: an examination of alterations in fermentation products and substrate losses at various time points. J Anim Sci 84, 1110-1118. 
36. Hvidberg A, Nielsen MT, Hilsted J, et al. (1994) Effect of glucagon-like peptide-1 (proglucagon 78-107amide) on hepatic glucose production in healthy man. Metabolism 43, 104-108.

37. Ørskov C, Rabenhøj L, Wettergren A, et al. (1994) Tissue and plasma concentrations of amidated and glycine-extended glucagon-like peptide I in humans. Diabetes 43, 535-539.

38. Hernot DC, Dumon HJ, Biourge VC, et al. (2006) Evaluation of association between body size and large intestinal transit time in healthy dogs. Am J Vet Res 67, 342-347.

39. Williams BA, Verstegen MWA \& Tamminga S (2001) Fermentation in the large intestine of single-stomached animals and its relationship to animal health. Nutr Res Rev 14, 207-227.

40. Macfarlane GT, Gibson GR, Beatty E, et al. (1992) Estimation of short-chain fatty acid production from protein by human intestinal bacteria based on branched-chain fatty acid measurements. FEMS Microbiol Ecol 101, 81-88.

41. Flickinger AE, Schreijen EMWC, Patil AR, et al. (2003) Nutrient digestibilities, microbial populations, and protein catabolites as affected by fructan supplementation of dog diets. J Anim Sci 81, 2008-2018.

42. Verlinden A, Hesta M, Hermans JM, et al. (2006) The effects of inulin supplementation of diets with or without hydrolysed protein sources on digestibility, faecal characteristics, haematology and immunoglobulins in dogs. Br J Nutr 96, 936-944.

43. Stoeckel LE, Weller RE, Giddings M, et al. (2008) Peptide YY levels are associated with appetite suppression in response to long-chain fatty acids. Physiol Behav 93, 289-295.

44. Stock S, Leichner P, Wong ACK, et al. (2005) Ghrelin, peptide YY, glucose-dependent insulinotropic polypeptide, and hunger responses to a mixed meal in anorexic, obese, and control female adolescents. J Clin Endocrinol Metab 90, 2161-2168.

45. Weickert MO, Spranger J, Holst JJ, et al. (2006) Wheat-fibreinduced changes of postprandial peptide YY and ghrelin responses are not associated with acute alterations of satiety. Br J Nutr 96, 795-798.

46. Smeets AJ, Soenen S, Luscombe-Marsh ND, et al. (2008) Energy expenditure, satiety, and plasma ghrelin, glucagon-like peptide 1 , and peptide tyrosine-tyrosine concentrations following a single high-protein lunch. J Nutr 138, 698-702.

47. Veldhorst M, Smeets A, Soenen S, et al. (2008) Protein-induced satiety: effects and mechanisms of different proteins. Physiol Behav 94, 300-307.
48. Onaga T, Zabielski R \& Kato S (2002) Multiple regulation of peptide YY secretion in the digestive tract. Peptides 23, 279-290.

49. Karaki S, Mitsui R, Hayashi H, et al. (2006) Short-chain fatty acid receptor, GPR43, is expressed by enteroendocrine cells and mucosal mast cells in rat intestine. Cell Tissue Res 324, 353-600.

50. Keenan MJ, Zhou J, McCutcheon KL, et al. (2006) Effects of resistant starch, a non-digestible fermentable fiber, on reducing body fat. Obesity 14, 1523-1534.

51. Delzenne NM, Cani PD, Daubioul C, et al. (2005) Impact of inulin and oligofructose on gastrointestinal peptides. $\mathrm{Br} \mathrm{J} \mathrm{Nutr}$ 93, S157-S161.

52. Gee JM \& Johnson IT (2005) Dietary lactitol fermentation increases circulating peptide YY and glucagon-like peptide-1 in rats and humans. Nutrition 21, 1036-1043.

53. Tappenden KA, Drozdowski LA, Thomson AB, et al. (1998) Short-chain fatty acid-supplemented total parenteral nutrition alters intestinal structure, glucose transporter 2 (GLUT2) mRNA and protein, and proglucagon mRNA abundance in normal rats. Am J Clin Nutr 68, 118-125.

54. Cani PD, Hoste S, Guiot Y, et al. (2007) Dietary non-digestible carbohydrates promote L-cell differentiation in the proximal colon of rats. Br J Nutr $\mathbf{9 8}, 32-37$.

55. Neary NM, Small CJ, Druce MR, et al. (2005) Peptide YY3-36 and glucagon-like peptide-1 7-36 inhibit food intake additively. Endocrinology 146, 5120-5127.

56. Roth JD, Coffey T, Jodka CM, et al. (2007) Combination therapy with amylin and peptide YY[3-36] in obese rodents: anorexigenic synergy and weight loss additivity. Endocrinology 148, 6054-6061.

57. Louis-Sylvestre J \& Le Magnen J (1980) A fall in blood glucose level precedes meal onset in free-feeding rats. Neurosci Biobehav Rev 4, 13-15.

58. Campfield LA, Smith FJ, Rosenbaum M, et al. (1996) Human eating: evidence for a physiological basis using a modified paradigm. Neurosci Biobehav Rev 20, 133-137.

59. Bergman EN (1990) Energy contributions of volatile fatty acids from the gastrointestinal tract in various species. Physiol Rev 70, 567-590.

60. Bleiberg B, Beers TR, Persson M, et al. (1992) Systemic and regional acetate kinetics in dogs. Am J Physiol Endocrinol Metab 262, E197-E202. 